\title{
Pregnancy outcome after antepartum diagnosis of oligohydramnios at or beyond thirty seven completed weeks in rural India
}

\author{
Kumud Ashok Gupta*, Rakesh Appasaheb Hasabe, Sumedha Aggarwal
}

Department of Obstetrics and Gynecology, NIMS University, Jaipur, Rajasthan, India

Received: 26 August 2015

Revised: 12 September 2015

Accepted: 27 October 2015

\section{*Correspondence:}

Dr. Kumud Ashok Gupta,

E-mail: roxy_100@rediffmail.com

Copyright: (C) the author(s), publisher and licensee Medip Academy. This is an open-access article distributed under the terms of the Creative Commons Attribution Non-Commercial License, which permits unrestricted non-commercial use, distribution, and reproduction in any medium, provided the original work is properly cited.

\begin{abstract}
Background: Amniotic fluid volume abnormalities may reflect a problem with fluid production or its circulation, such as underlying fetal or placental pathology. These volume extremes may be associated with increased risks for adverse pregnancy outcome. Some studies show that amniotic fluid index is a poor predictor of adverse outcome and some authors have not confirmed the association of adverse perinatal outcome with oligo-hydramnios. Thus this study is conducted to find out the value of oligohydramnios in perinatal outcome and maternal outcome in pregnancies beyond 37 completed weeks.

Methods: This study was done at department of Obstetrics and Gynaecology, NIMS hospital, Jaipur, Rajasthan, India, from January 2013 to January 2015 for a period of 24 months. Our analysis included a total of 200 antenatal women; both booked and unbooked were included in this study.

In this study 100 women with AFI $<5 \mathrm{~cm}$ were allotted into the study group and another 100 women with normal AFI were included into the control group. Labour was either spontaneous or induced in both study and control group . During labour intermittent auscultation of fetal heart rate was done to detect any signs of fetal distress. Artificial rupture of membranes was done in active phase of labour to notice the grade of liquor and progress of labour was monitored on a partogram. Mode of delivery and intrapartum complications were noted. At birth neonate was assessed using 5 minute APGAR score, birth weight was recorded and neonate who were admitted into NICU were followed until discharge.

Results: Oligohydramnios i.e., AFI $<5 \mathrm{~cm}$ measured by ultrasonography in term pregnancies is associated with adverse perinatal outcome. The risks of meconium staining of liquor, intrapartum fetal distress, operative delivery and perinatal mortality are significantly higher in patients with AFI $<5 \mathrm{~cm}$, compared to those with normal AFI.

Conclusions: Determination of AFI can be used as an adjunct to other fetal surveillance methods. It helps to identify those infants at risk of poor perinatal outcome. Determination of AFI is a valuable screening test for predicting fetal distress in labour requiring cesarean section.
\end{abstract}

Keywords: Oligohydramnios, Perinatal outcome and maternal outcome, Determination of AFI, Amniotic fluid volume abnormalities

\section{INTRODUCTION}

Amnionic fluid serves several roles during pregnancy. It creates a physical space for fetal movement, which is necessary for normal musculoskeletal development. It permits fetal swallowing - essential for gastrointestinal tract development, and fetal breathing - necessary for lung development. Amnionic fluid guards against umbilical cord compression and protects the fetus from trauma. It even has bacteriostatic properties. Amnionic fluid volume abnormalities may reflect a problem with fluid production or its circulation, such as underlying 
fetal or placental pathology. These volume extremes may be associated with increased risks for adverse pregnancy outcome. Amnionic fluid volume increases from approximately $30 \mathrm{~mL}$ at 10 weeks to $200 \mathrm{~mL}$ by 16 weeks and reaches $800 \mathrm{~mL}$ by the mid-third trimester. ${ }^{1}$

Some studies show that amniotic fluid index is a poor predictor of adverse outcome $e^{2-5}$ and some authors have not confirmed the association of adverse perinatal outcome with oligohydramnios. ${ }^{6-9}$ Thus this study is conducted to find out the value of oligohydramnios in perinatal outcome and maternal outcome in pregnancies beyond 37 completed weeks.

\section{METHODS}

This study was done at department of Obstetrics and Gynaecology, NIMS hospital Jaipur, India, from January 2013 to January 2015 for a period of 24 months. Our analysis included a total of 200 antenatal women; both booked and unbooked were included in this study.

\section{Inclusion Criteria}

1. Thirty seven completed weeks of gestation.

2. Amniotic fluid index of $\leq 5 \mathrm{~cm}$.

3. Intact membranes.

4. Singleton pregnancy with cephalic presentation.

5. Pregnancy induced hypertension.

\section{Exclusion Criteria}

1. Gestational age less than 37 completed weeks.

2. Associated fetal malformations.

3. Ruptured membranes.

4. Malpresentation.

5. Multiple gestation.

A detailed history and examination were done. All required investigations were done. Oligohydramnios confirmed by measuring AFI or single deepest pocket. Routine management in form of rest, left lateral position, oral and intravenous hydration and control of etiological factor was done if present. Fetal surveillance was done by USG, modified biophysical profile and Doppler. Decision of delivery by either induction or elective or emergency LSCS was done as per required. Some patients were already in labour and others were allowed going into spontaneous labour. Cases were than studied for maternal and perinatal outcome.

Amnionic fluid volume evaluation is a component of every standard sonogram performed in the second or third trimester. Volume is typically assessed semiquantitatively, by measuring either a single deepest pocket or the amnionic fluid index-AFI. ${ }^{10}$

\section{Single deepest pocket}

This is also called the maximum vertical pocket. The ultrasound transducer is held perpendicular to the floor and parallel to the long axis of the pregnant woman. In the sagittal plane, the largest vertical pocket of fluid is identified.

The normal range for single deepest pocket that is most commonly used is 2 to $8 \mathrm{~cm}$, with values above and below this indicating hydramnios and oligohydramnios, respectively.

\section{Amnionic fluid index (AFI)}

This was described by Phelan and coworkers in 1987 more than 25 years ago, and it remains one of the most commonly used methods of amnionic fluid volume assessment. As with the single deepest fluid pocket measurement, the ultrasound transducer is held perpendicular to the floor and parallel to the long axis of the pregnant woman. The uterus is divided into four equal quadrants - the right- and left-upper and lower quadrants, respectively. The AFI is the sum of the single deepest pocket from each quadrant. The normal range for AFI that is most commonly used is 5 to $24 \mathrm{~cm}$, with values above and below this indicating hydramnios and oligohydramnios, respectively. ${ }^{10}$

Repeat examination by a single observer results in best accuracy. Other factors that affect AFI reproducibility are measuring narrow pockets, measuring into gray or 'fuzzy' tangential section of placenta or fetal parts and measuring the same pocket twice in adjacent quadrants. The effect of fetal movement during the scanning process may change the AFI of $1.5-2.5 \mathrm{~cm}$. $^{11}$ The AFI values obtained with the sector or curvilinear transducers were as reliable as those obtained with gold standard linear transducer. $^{12}$

In this study 100 women with $\mathrm{AFI}<5 \mathrm{~cm}$ were allotted into the study group and another 100 women with normal AFI were included into the control group. Labour was either spontaneous or induced in both study and control group. During labour intermittent auscultation of fetal heart rate was done to detect any signs of fetal distress. Artificial rupture of membranes was done in active phase of labour to notice the grade of liquor and progress of labour was monitored on a partogram. Mode of delivery and intrapartum complications were noted. At birth neonate was assessed using 5 minute APGAR score, birth weight was recorded and neonate who were admitted into NICU were followed until discharge.

\section{RESULTS}

Various factors were studied and compared between two groups as follows. 
This Pie-Chart shows that Oligohydramnios was more common in unbooked ases. In other words proper antenatal care reduces the risk of Oligohydramnios.

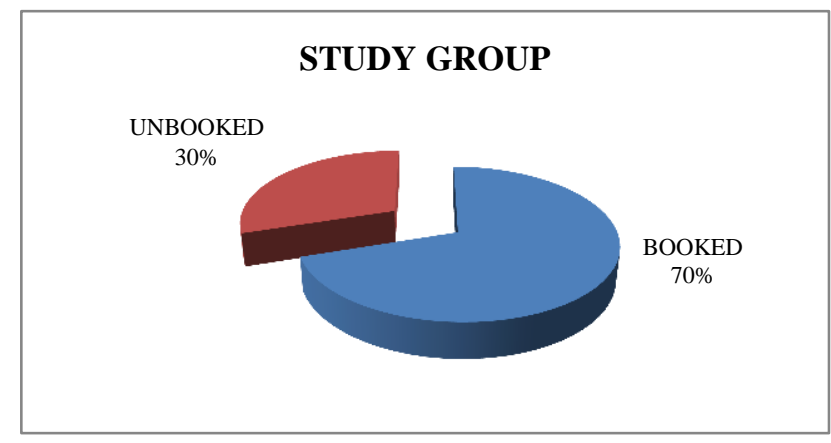

Figure 1(a): Booked and unbooked cases in study group.

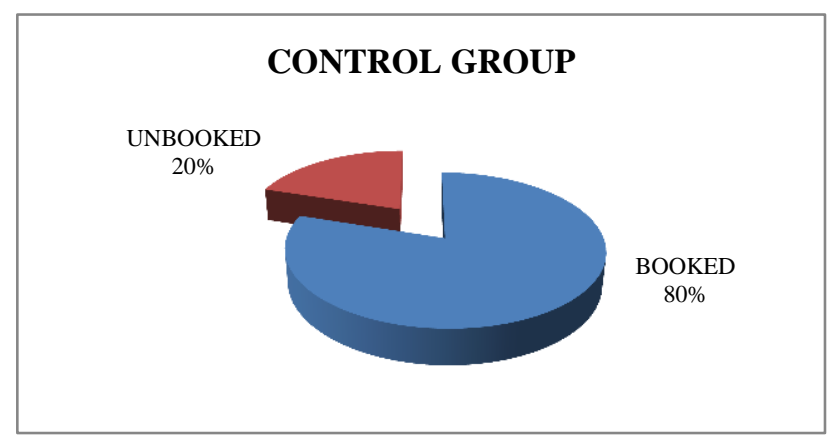

Figure 1(b): Booked and unbooked cases in control group.

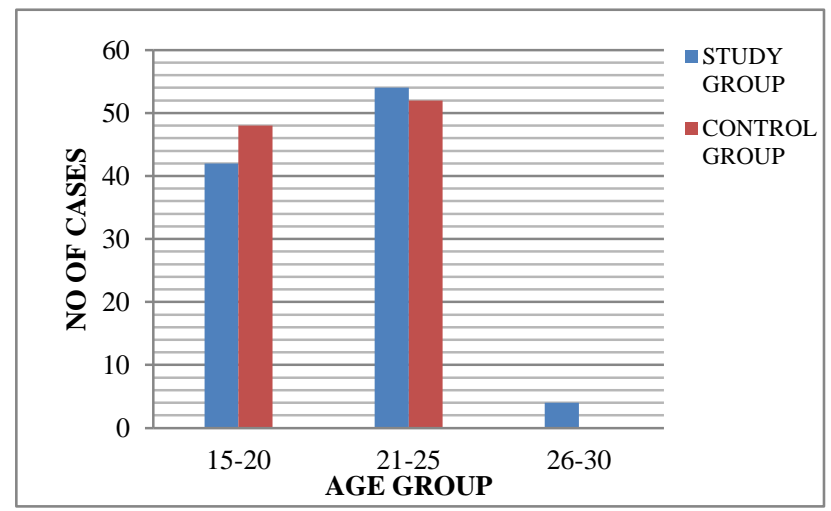

Figure 2: Age distribution and amniotic fluid index.

The above figure shows that there is no significant difference found in the age group of patients among the study and control.

So our study suggests that there was significant association between prolonged pregnancy and oligohydramnios.

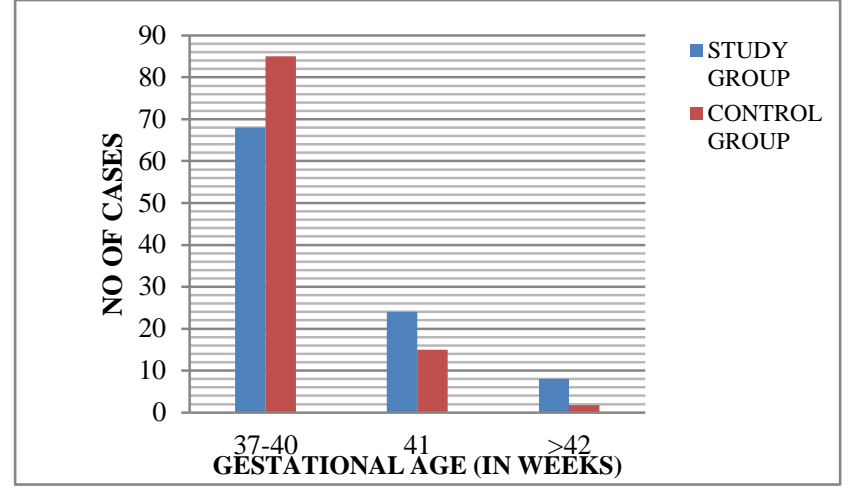

Figure 3: Gestational age and its influence over AFI.

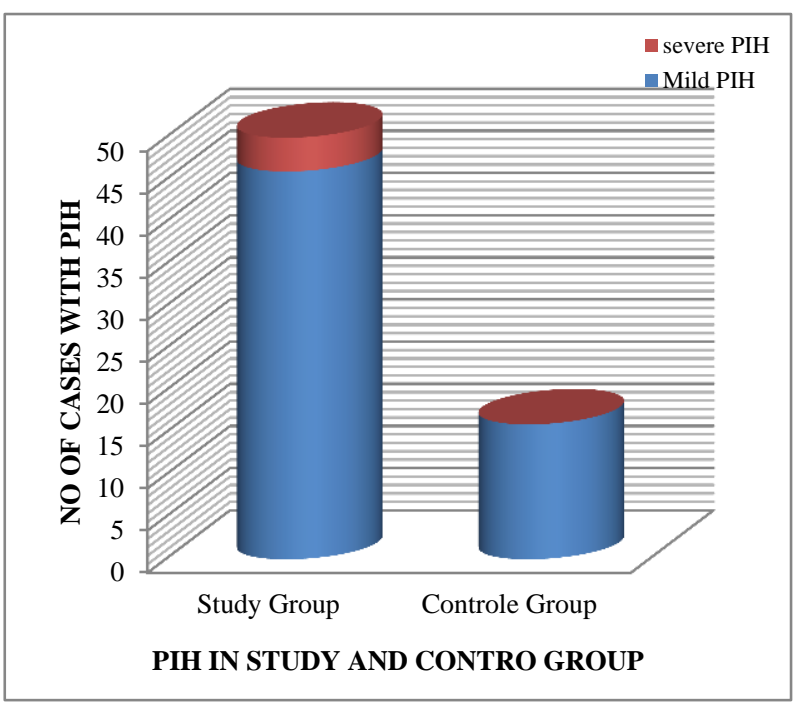

Figure 4: Incidence of pregnancy induced hypertension.

$50 \%$ of the study group had PIH, which suggests significant association of Oligohydramnios and PIH. This is compared to the study of Kamala Ganesh et al and found significant association of PIH with oligohydramnios. ${ }^{13}$

The induction of labour was significantly high in study group (54\%). This study is compared to the study of Casey et al. ${ }^{14}$

Our study suggests significant relationship between Oligohydramnios and LSCS. Operative interferences were more in study group as compared to the control group.

On analysing the indications for caesarean section fetal distress was found to be dominant indication in study group $(58 \%)$ when compared to control $(30 \%)$. The other indications for caesarean sections to both study and control group are PIH, cephalo-pelvic disproportion and failed induction. 


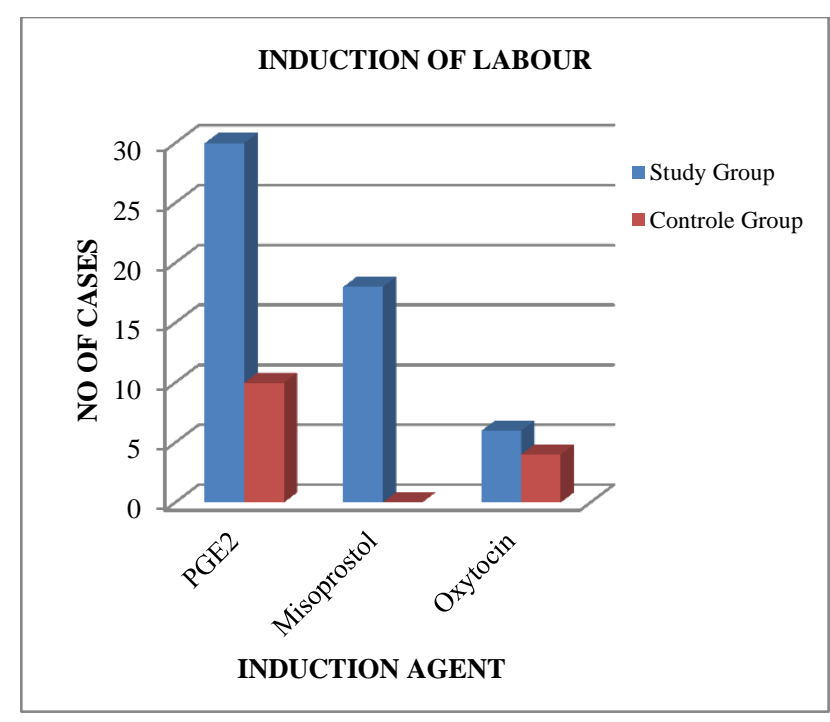

Figure 5: Induction of labour.

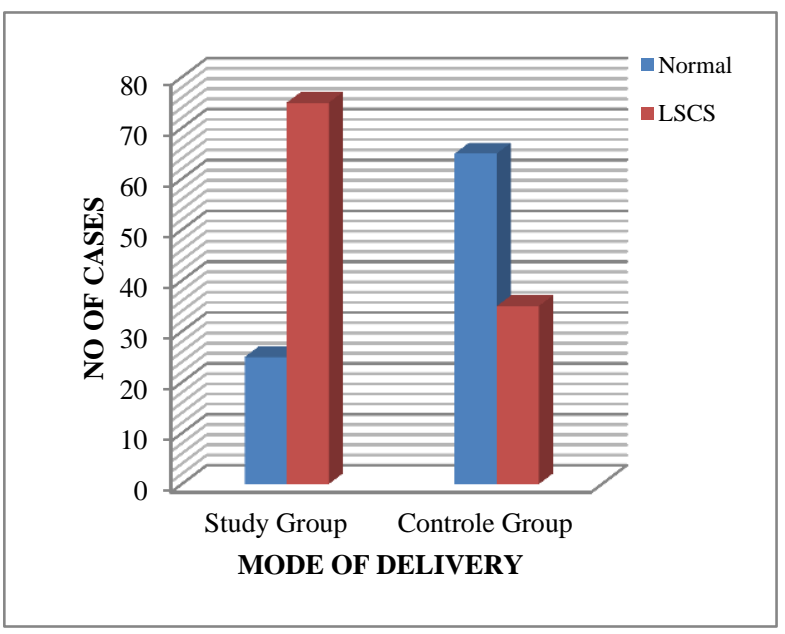

Figure 6: Mode of delivery.

The incidence of meconium stained liquor was significantly higher in study group as compared to control group.

APGAR scores were compared between study group and control group. $20 \%$ of the cases in study group had APGAR less than 7 , compared to $5 \%$ of cases in control group.

The incidence of NICU admissions in study group (40\%) was significantly higher than control group (12\%). Also incidence of MAS was higher in study group (10\%), control group did not have any MAS.

Our study suggested significant incidence of LBW (low birth weight) in study group as compared to control group.

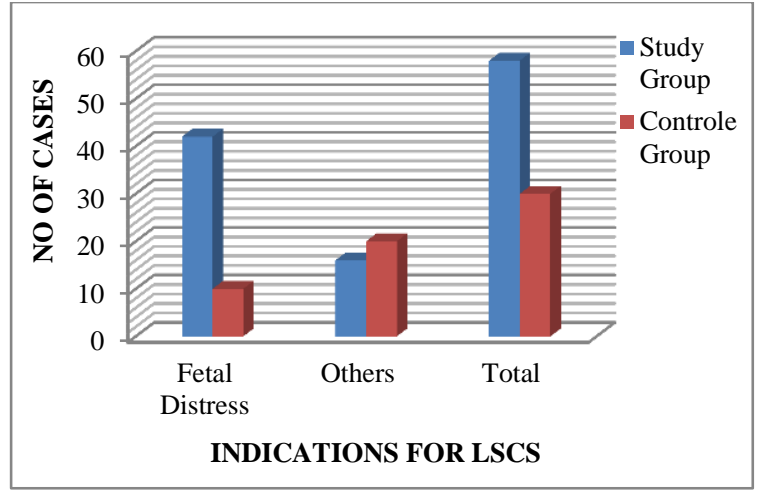

Figure: 7 Indications of caesarean section.

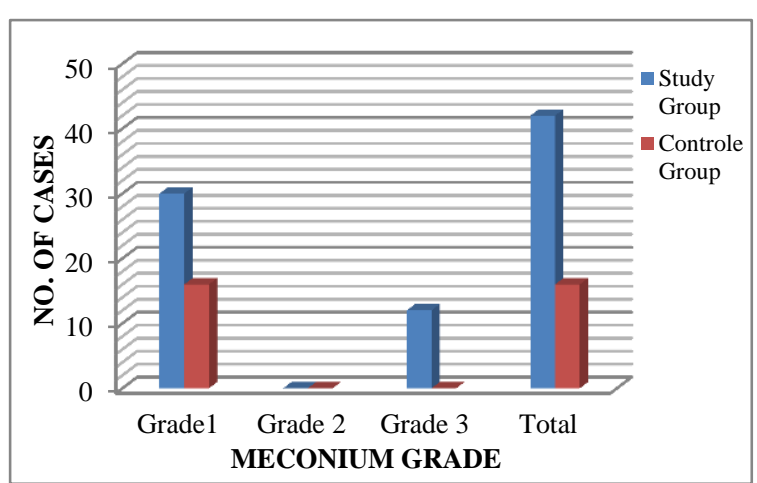

Figure 8: Meconium stained liquor grading.

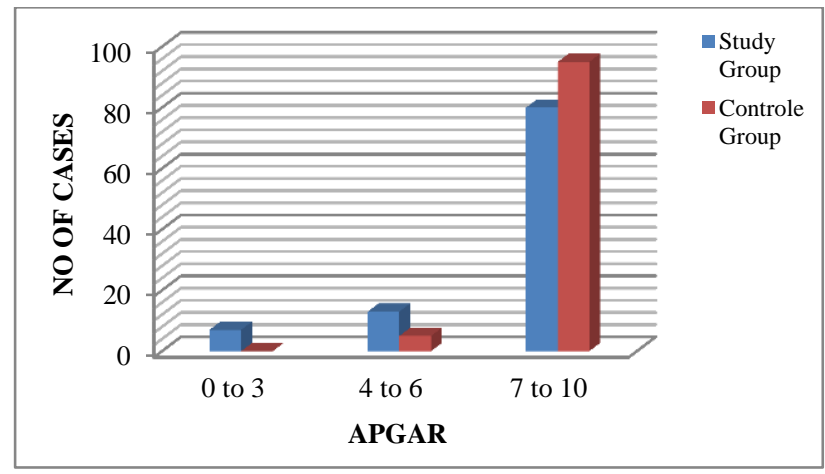

Figure: 9 Low amniotic fluid index and 5 min APGAR score.

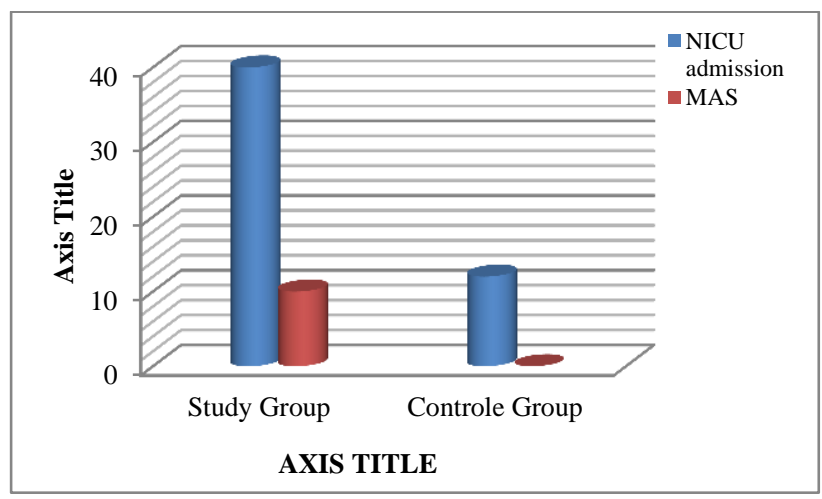

Figure 10: NICU admission and meconium aspiration syndrome. 


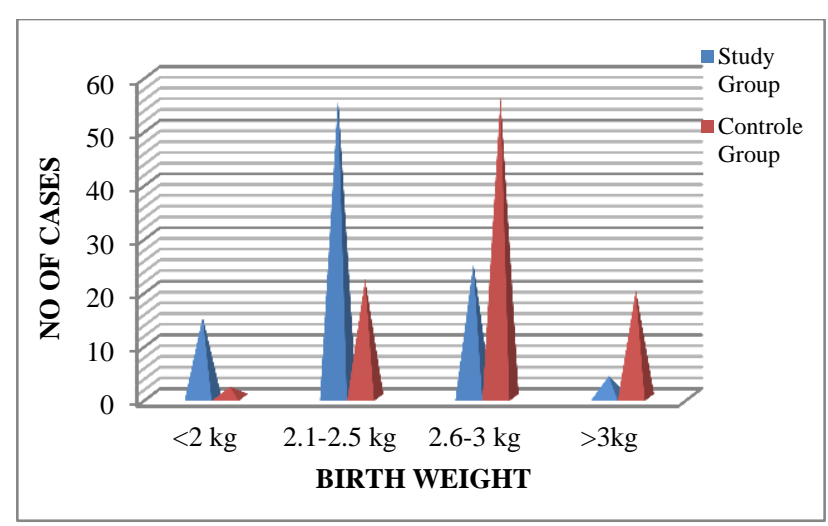

Figure 11: Low amniotic fluid index and birth weight.

\section{DISCUSSION}

Oligohydramnios is associated with increased risk of adverse pregnancy outcomes. Casey and colleagues (2000) found that an AFI $\leq 5 \mathrm{~cm}$ complicated 2 percent of pregnancies undergoing sonography at Parkland Hospital after 34 weeks. Newborns from pregnancies with oligohydramnios were more likely than those with AFIs $>5 \mathrm{~cm}$ to have malformations. Even in the absence of malformations, higher rates of fetal stillbirth, growth restriction, nonreassuring heart rate pattern, and meconium aspiration syndrome were noted. Petrozella and associates in 2011, similarly reported that with an AFI $\leq 5 \mathrm{~cm}$ identified between 24 and 34 weeks, there was increased risk for stillbirth, spontaneous or medically indicated preterm birth, heart rate pattern abnormalities, and growth restriction. In a meta-analysis of 18 studies comprising more than 10,000 pregnancies, Chauhan and co-workers in 1999 found that women with oligohydramnios had a twofold increased risk for cesarean delivery for fetal distress and a fivefold risk for an Apgar score $<7$ at 5 minutes compared with pregnancies with normal AFI. ${ }^{15}$

The limitations of study include:

1. Exactly satisfied inclusion and exclusion criteria.

2. The use of backup surveillance methods like scalp blood sampling and acoustic stimulation and amnioinfusion would have altered the outcome.

Amniotic fluid volume is a predictor of fetal tolerance in labour and its decrease is associated with increased risk of abnormal heart rate and meconium stained fluid. So it is recommended to identify oligohydramnios and treat it promptly. Also these patients are to be given special attention during labour.

\section{CONCLUSIONS}

Oligohydramnios i.e., AFI $<5 \quad \mathrm{~cm}$ measured by ultrasonography in term pregnancies is associated with adverse perinatal outcome. The risks of meconium staining of liquor, intrapartum fetal distress, operative delivery and perinatal mortality are significantly higher in patients with AFI $<5 \mathrm{~cm}$, compared to those with normal AFI. Determination of AFI can be used as an adjunct to other fetal surveillance methods. It helps to identify those infants at risk of poor perinatal outcome. Determination of AFI is a valuable screening test for predicting fetal distress in labour requiring cesarean section.

Funding: No funding sources

Conflict of interest: None declared

Ethical approval: The study was approved by the Institutional Ethics Committee

\section{REFERENCES}

1. 'Amniotic Fluid', in Cunningham, Leveno, Bloom, Spong, Dashe, Hoffman, Casey, Sheffield (ed.) Williams Obstetrics. United states: Mc Graw Hill Education, 485.

2. Chamberlain PF, Manning FA, Morrison I, et al. Ultrasound evaluation of amniotic fluid volume. Am J Obstet Gynecol. 1984;150:245-9.

3. Chamberlain PF, Manning FA, Morrison I, et al. Ultrasound evaluation of amniotic fluid volume II the relationship of increased amniotic fluid volume to perinatal outcome. Am J Obstet Gynecol. 1984;150:250-4.

4. Banks EH, Miller DA. Perinatal risks associated with borderline AFI. Am J Obstet Gynecol 1999;18:1461.

5. Casey BM. Pregnancy outcomes after antepartum diagnosis of oligohydramnios at or beyond 34 weeks' gestation. Am J Obstet Gynecol. 2000;182:909-12.

6. Locatelli A, Zaqarella A, Toso L, Assi F, Ghidini A, Biffi A. Serial assessment of AFI in uncomplicated term pregnancies: Prognostic value of amniotic fluid reduction. J Matern Fetal Neonatal Med. 2004; 15:233-6.

7. Chauhan SP, Hendrix NW, Morrison JC, Magann $\mathrm{EF}$, Devoe LD. Intrapartum oligohydramnios does not predict adverse peripartum outcome among high risk parturient. Am J Obstet Gynaecol. 1997;176:1130-8.

8. Rainford M, Adair R, Scialli AR, Ghidini A, Spongy CY. Amniotic fluid index in the uncomplicated term pregnancy. Prediction of outcome. J Reprod Med. 2001;46:589-92.

9. Ott WJ. Re-evaluation of the relationship between amniotic fluid volume and perinatal outcome. Am J Obstet Gynecol. 2005;192:1803-9.

10. 'Amniotic Fluid', in Cunningham, Leveno, Bloom, Spong, Dashe, Hoffman, Casey, Sheffield (ed.) Williams Obstetrics. United states: Mc Graw Hill Education. 1997: 487-488.

11. Wax JR, Castigan K, Callan NA, et al. Effect of fetal movement on the AFI. Am J Obst \& Gynec.1993;168:188-9.

12. Del Valle GO, Bateman L, Gandier FL, et al. Comparision of three types of ultrasound transducers in evaluating the amniotic fluid index. J. Reprod.Med.1994;39:869-72. 
13. Ganesh K, Dhavan U, Gupta N. Qualitative amniotic fluid volume determination by USGin pregnancy complicated with hypertension and its correlation with fetal outcome. J Obstet Gynecol. 1989;XXX1X:34-7.

14. Casey BM. Pregnancy outcomes after antepartum diagnosis of oligohydramnios at or beyond 34 weeks gestation Am J Obstet Gynecol. 2000;182;909-1.

15. 'Amniotic Fluid', in Cunningham, Leveno, Bloom, Spong, Dashe, Hoffman, Casey, Sheffield (ed.)
Williams Obstetrics. United states: Mc Graw Hill Education, 498.

Cite this article as: Gupta KA, Hasabe RA, Aggarwal S. Pregnancy outcome after antepartum diagnosis of oligohydramnios at or beyond thirty seven completed weeks in rural India. Int J Reprod Contracept Obstet Gynecol 2015;4:1811-6. 